\footnotetext{
${ }^{1}$ Professor, Griffith School of Engineering, Griffith University Gold Coast Campus, Queensland, QLD 4222, Australia

${ }^{2}$ Postgraduate student, Griffith School of Engineering, Griffith University Gold Coast Campus, Queensland, QLD 4222, Australia.
} sediments

\author{
D-S Jeng ${ }^{1}$ and H Y Zhao ${ }^{2}$
}

\section{ABSTRACT}

A two-dimensional 2-D porous model was developed to investigate the accumulation of pore pressure in marine sediments, in which the volume-averaged Reynolds-averaged NavierStokes (VARANS) equations were used as the governing equations for the wave motion and Biot's consolidation theory was used for the porous seabed. Unlike most of the previous investigations on the accumulation of pore pressure in which the amplitude of the shear stress over the wave period was used in the source term, in this study, the source term was re-defined as a time-dependent function using the phase-resolved oscillatory shear stresses. Overall good agreement of both oscillatory and residual pore pressures with previous analytical solutions and experimental data demonstrated the reliability of the model for the prediction of wave-induced pore pressure accumulation. For the case with progressive wave loadings, the liquefaction zone related to the initial incident of the wave phases was formed as a 2-D pattern during the first liquefaction wave period. This 2-D pattern became one-dimensional after one wave period, decreasing progressively, to a constant value after a number of wave cycles. For the case with standing wave loadings, a 2-D liquefaction zone occurs first in the region where the shear strains are highest. Eventually, this 2-D pattern becomes continuous, which implies that even the soil in the anti-node section can be liquefied. Compared with the seabed response under linear wave loading, the pore pressure more easily accumulates to a higher value under non-linear wave loading because of the higher peak in the shear strains. Parametric studies indicate that,

\title{
Two-dimensional model for accumulation of pore pressure in marine
}


both the wave characteristics and soil properties affect the maximum relative liquefaction depth

$\left(z_{L} / h\right)$ significantly. In general, the maximum liquefaction depth increases as the wave height and as the wave length increase and in shallow water within the seabed, which has a lower permeability and lower relative density.

Keywords: wave-induced seabed response; residual liquefaction; phase-resolved instant shear stress; porous seabed; VARANS equations; Biot's theory.

\section{INTRODUCTION}

Wave-induced seabed instability has become an increasingly important issue in the design of foundations around offshore infrastructures. Two mechanisms for wave-induced liquefaction have been reported in previous laboratory studies (Zen and Yamazaki 1990), depending upon how the excess pore pressure is generated. One is transient (or oscillatory) liquefaction, which is usually associated with unsaturated marine soils. It is momentary liquefaction that occurs in the seabed under wave troughs when the encapsulated air dissipates the pressure causing a sharp upwardly directed pressure gradient. The other mechanism is normally seen in fully saturated soils. It is a result of the build-up of excess pore pressure caused by the volumetric compaction caused by the action of cyclic wave loading. In this study, we will focus on the residual liquefaction from the second mechanism.

Numerous laboratory experiments (Tzang 1998; Sumer et al. 1999; Sumer et al. 2012; Sumer 2014) have reported the wave-induced pore pressure build-up mechanism and the existence of residual liquefaction. Based on wave flume tests (Sumer et al. 1999; Sumer et al. 2012), three primary factors have been identified that affect the accumulation of pore pressure, i.e., the cyclic shear stress ratio $\left(\tau / \sigma_{0}^{\prime}\right)$, the period of cyclic loading, and the number of loading cycles required to reach residual liquefaction. Seed and Rahman (1978) developed a simple one-dimensional (1D) finite element model for earthquake-induced liquefaction to describe the buildup of pore pressure under progressive waves. This model has been further extended analytically and numerically to examine wave-induced residual soil response. McDougal et al. (1989) has investigated a set of analytical solutions for wave-induced pore pressure buildup in a 
uniform soil layer. Cheng et al. (2001) proposed an analytical solution to re-examine the solu-

tion developed by McDougal et al., noting that the small error of shear stress can lead to a large error in the accumulated pore pressure. Sumer and Fredsøe (2002) has developed an analytical solution using Fourier transforms to evaluate the buildup of pore pressure, based on Biot's consolidation equations. Jeng et al. (2007) re-examined the wave-induced residual soil response by developing both an analytical approximation and a numerical solution, thereby providing a better prediction than the previous solutions (McDougal et al. 1989; Cheng et al. 2001). It is noted that the Sumer and Fredsøe (2002) and the Jeng et al. (2007) models are identical, but with different forms and approaches.

Standing waves often occurs in front of an impervious vertical wall or on the ocean side of composite breakwaters, which are formed by the combination of the reflected waves meeting the incoming waves. Compared with previous investigations for progressive wave-induced liquefaction, studies on the standing wave-induced seabed liquefaction have been relatively rare. One of the leading studies for standing wave induced seabed liquefaction was performed by Sekiguchi et al. (1995), in which the derived a closed-form solution considering 1D poroelastoplasticity under standing waves. Sassa and Sekiguchi (2001) presented a 2-D elastoplastic constitutive model in a finite element analysis of wave-induced liquefaction in sand beds, comparing the numerical solutions with experimental measurements conducted in a centrifuge wave tank (Sassa and Sekiguchi 1999). Their study showed that the rotation of the principal stress axes in the sand was important in the prediction of wave-induced residual soil response under progressive wave loads. Overall, their results were esatisfactory, except for the maximum residual pore pressure in the soil at the antinodal section. Their experiments showed that the soil can liquefy at the antinodal section; however, the opposite behavior was predicted by their numerical results. Recently, Kirca et al. (2013) presented the results of an experimental study of the seabed residual liquefaction under standing wave loads. This is one of a few available in the literature for standing wave-induced pore pressures.

In all the aforementioned studies, except Sassa and Sekiguchi (2001), for wave-induced 
residual pore pressures in marine sediments, the source term was considered as a time-independent

function with the maximum amplitude of the oscillatory shear stress. Therefore, the oscillatory and residual mechanisms were not coupled, although they affect each other. In this study, we define the source term as a time-dependent function with the phase-resolved oscillatory shear stress and derive the boundary value problem in 2-D. The numerical results from the present model are verified using the previous analytical solution and the experimental data first. Then, the effect of the nonlinear wave components on the accumulation of the wave-induced pore pressure investigated. Finally, the process of the development of the liquefaction zone and the effect of thewave characteristics and the soil properties on the wave-induced maximum liquefaction depth is suggested.

\section{THEORETICAL FORMULATIONS}

The phenomenon of ocean waves propagating over a porous seabed is shown in Figure 1. It is assumed that any deformations of the porous seabed are not large and therefore do not affect the wave-seabed interactions. Non-linear waves are simulated by the previous wave model, and the residual mechanism of the seabed response is modeled by a poro-elastic model. Both wave and seabed models are integrated into a single model.

\section{Wave model}

The flowof the incompressible fluid is described by the based on the volume-averaged Reynolds averaged Navier-Stokes (VARANS) equations (Lin and Liu 1999) for the mass conservation and momentum conservation as follows: 


$$
\begin{aligned}
& \frac{\partial\left\langle\bar{u}_{f i}\right\rangle}{\partial x_{i}}=0, \\
& \frac{\partial\left\langle\bar{u}_{f i}\right\rangle}{\partial t}+\frac{\partial\left\langle\bar{u}_{f j}\right\rangle}{n\left(1+c_{A}\right)} \frac{\partial\left\langle\bar{u}_{f i}\right\rangle}{\partial x_{j}}=\frac{1}{1+c_{A}}\left[-\frac{n}{\rho_{f}} \frac{\partial\langle\bar{p}\rangle^{f}}{\partial x_{i}}\right. \\
& \left.\quad-\frac{\partial\left\langle\bar{u}_{f i}^{\prime} u_{f j}^{\prime}\right.}{\partial x_{j}}+\frac{1}{\rho_{f}} \frac{\partial\left\langle\bar{\tau}_{f i j}\right\rangle}{\partial x_{j}}+n g_{i}\right]-\frac{\left\langle\bar{u}_{f i}\right\rangle}{1+c_{A}}\left[\frac{\alpha_{f}^{\prime}(1-n)^{2}}{n^{2} d_{50}^{2}}\right. \\
& \left.\quad+\frac{\beta_{f}(1-n)}{n^{2} d_{50}} \sqrt{\left\langle\bar{u}_{f 1}\right\rangle^{2}+\left\langle\bar{u}_{f 2}\right\rangle^{2}}\right]
\end{aligned}
$$

where $u_{f i}$ is the flow velocity, $x_{i}$ are the Cartesian coordinates, $t$ is the time, $\rho_{f}$ is the density of water, $p$ is the pressure, $g_{i}$ is gravitational acceleration, $n$ and $d_{50}$ are the porosity and equivalent mean diameter of the porous material, respectively, $c_{A}$ is the added mass coefficient, calculated by $c_{A}=0.34(1-n) n, \alpha_{f}^{\prime}=200$ and $\beta_{f}=1.1$ are empirical coefficients associated with the linear and nonlinear drag force, respectively, and $\tau_{f i j}$ is the viscous stress tensor of the mean flow, which can be defined as follows:

$$
\tau_{f i j}=v_{f}\left(\frac{\partial \bar{u}_{f i}}{\partial x_{j}}+\frac{\partial \bar{u}_{f j}}{\partial x_{i}}\right)
$$

where $v_{f}$ is the molecular viscosity. The over-bar represents the ensemble average in the case of waves and the prime denotes turbulent fluctuations induced by the ensemble mean. Note that because the VARANS equations are also valid for steady or uncyclic unsteady flow scenarios, in this case, the over-bar denotes time averaging rather than ensemble averaging. The symbols \langle\rangle and \langle\rangle$^{f}$ stand for Darcy's volume averaging operator and the intrinsic averaging operator, respectively, and are defined as follows:

$$
\langle a\rangle=\frac{1}{V} \int_{V_{f}} a d v, \text { and }\langle a\rangle^{f}=\frac{1}{V^{f}} \int_{V_{f}} a d v
$$

where $V$ is the total averaging volume, and $V_{f}$ is the portion of $V$ that is occupied by the fluid. The relationship between Darcy's volume averaging operator and intrinsic volume averaging 
is $\langle a\rangle=n\langle a\rangle^{f}$. The turbulent kinetic energy $(k)$ and the turbulent dissipation rate $\left(\epsilon_{f}\right)$ can be determined from the $k-\epsilon_{f}$ equations as follows:

$$
\begin{aligned}
& \frac{\partial\langle k\rangle}{\partial t}+ \frac{\partial\left\langle\bar{u}_{f j}\right\rangle}{n} \frac{\partial\langle k\rangle}{\partial x_{j}}+\frac{\partial\left\langle\bar{u}_{f j}\right\rangle}{n} \frac{\partial\langle k\rangle}{\partial x_{j}}=-\frac{\left\langle\overline{u_{f i}^{\prime} u_{f j}^{\prime}}\right.}{n} \frac{\partial\left\langle\bar{u}_{f i}\right\rangle}{\partial x_{j}} \\
&+\frac{\partial}{\partial x_{j}}\left[\left(\frac{\partial\left\langle v_{e t}\right\rangle}{\sigma_{k}}+v_{e}\right) \frac{\partial k}{\partial x_{j}}\right]-\left\langle\epsilon_{f}\right\rangle+n \epsilon_{f \infty}
\end{aligned}
$$

where $v_{e t}$ is the eddy viscosity and $v_{e}$ is the dynamic viscosity, which can be expressed as $v_{f} / \rho_{f}$. The empirical coefficients $C_{1 \epsilon}, C_{2 \epsilon}, \sigma_{\epsilon}$ and $\sigma_{k}$ are 1.44, 1.92, 1.3 and 1.0, respectively, and are estimated from stationary flow experiments (Rodi 1980). The $\epsilon_{f_{\infty}}$ and $k_{\infty}$ are defined as follows:

$$
\begin{gathered}
\epsilon_{f \infty}=39.0 \frac{(1-n)^{2.5}}{n}\left(\left\langle\overline{u_{1}}\right\rangle^{2}+\left\langle\overline{u_{2}}\right\rangle^{2}\right)^{1.5} \frac{1}{d_{50}} \\
k_{\infty}=3.7 \frac{1-n}{\sqrt{n}}\left(\left\langle\overline{u_{1}}\right\rangle^{2}+\left\langle\overline{u_{2}}\right\rangle^{2}\right)
\end{gathered}
$$

Appropriate boundary conditions are required to solve the wave field. With respect to the mean flow field, the no-slip boundary condition is imposed on the seafloor surface $\left(u_{f i}=0\right)$. Neglecting the effect of air flow, the zero-stress condition is adopted on the mean free surface, $\left(\tau_{f i j}=0\right)$. For the turbulence field, the log-law distribution of mean tangential velocity in the turbulent boundary layer is imposed near the rigid boundary. Both the turbulent kinetic energy $(k)$ and its dissipation rate $\left(\epsilon_{f}\right)$ on the free surface are implemented with zero gradient boundary conditions, (i.e., $\frac{\partial k}{\partial n}=\frac{\partial \epsilon_{f}}{\partial n}=0$, in which $n$ is the unit normal on the free surface). The damping zone is located at two vertical boundaries which are far from the region concerned. More detailed implementations on the boundary conditions for the wave model are discussed by Lin and Liu (1999). 


\section{Seabed model}

\section{Wave-induced soil response}

Based on the poro-elastic theory by Biot (1941), the governing equations for the force equilibrium in the soil can be written as follows:

$$
\begin{aligned}
& G \nabla^{2} u_{s}+\frac{G}{1-2 \mu_{s}} \frac{\partial}{\partial x}\left(\frac{\partial u_{s}}{\partial x}+\frac{\partial w_{s}}{\partial z}\right)=\frac{\partial p_{s}}{\partial x} \\
& G \nabla^{2} w_{s}+\frac{G}{1-2 \mu_{s}} \frac{\partial}{\partial z}\left(\frac{\partial u_{s}}{\partial x}+\frac{\partial w_{s}}{\partial z}\right)=\frac{\partial p_{s}}{\partial z}
\end{aligned}
$$

where $\left(u_{s}, w_{s}\right)$ are the soil displacements in the $x$ - and $z$-directions, respectively; $p_{s}$ is the pore pressure; $\mu_{s}$ is Poisson's ratio; and $G$ is the shear modulus of the soil.

The wave-induced soil response consists of two components, a transident (oscillatory) component and a residual (build-up) component. The total soil response can thus be expressed as follows:

$$
b=\tilde{b}+\bar{b}, \text { where } \bar{b}=\frac{1}{T} \int b d t
$$

where $T$ is the wave period, $b$ denotes the the wave-induced soil response variables (including soil displacements, stresses and pore pressures), $\tilde{b}$ represents the oscillatory component, and $\bar{b}$ represents the residual component. In the following sections, both components will be considered.

\section{Oscillatory soil response}

In this study, a saturated porous seabed is assumed to be hydraulically isotropic with the same permeability $K$ in all directions. With these assumpitions, the conservation of mass of pore fluid yields the following:

$$
\nabla^{2} \tilde{p}-\frac{\gamma_{w} n_{s} \beta_{s}}{K} \frac{\partial \tilde{p}_{s}}{\partial t}=\frac{\gamma_{w}}{K} \frac{\partial}{\partial t}\left(\frac{\partial \tilde{u}_{s}}{\partial x}+\frac{\partial \tilde{w}_{s}}{\partial z}\right)
$$

where $\tilde{p}$ is the wave-induced oscillatory pore pressure, $n_{x}$ is the soil porosity, $\gamma_{w}$ is the unit weight of water in the pore, and $\beta_{s}$ is the compressibility of the pore fluid, which is defined as 
follows:

$$
\beta_{s}=\frac{1}{K_{w}}+\frac{1-S}{P_{w 0}}
$$

145

where $K_{w}$ is the true modulus of elasticity of water (taken as $2 \times 10^{9} \mathrm{~N} / \mathrm{m}^{2}$ ), $P_{w o}$ is the absolute water pressure, and $S$ is the degree of saturation.

The wave-induced oscillatory soil response is obtained by solving equations (9), (10) and (12) with the appropriate boundary conditions. At the seabed surface $(z=0)$, the boundary conditions are as follows:

$$
\tilde{p}_{s}(x, 0 ; t)=P_{b}(x, t), \quad \tilde{\tau}_{s}(x, 0 ; t)=\tau_{f}(x, t), \quad \tilde{\sigma}_{s z}^{\prime}=0,
$$

where $p_{b}$ is the dynamic wave pressure amd $\tau_{f}$ is the wave-induced bottom shear stresses at the seabed surface.

At impermeable seabed bottom $(z=-h)$, the boundary conditions are expressed as follows:

$$
\frac{\partial \tilde{p}_{s}}{p z}=0=\tilde{u}_{s}=0=\tilde{w}_{s}
$$

\section{Residual soil response: Existing 1-D model}

By adopting the mechanism of wave-induced residual pore pressure accumulation proposed by Seed and Rahman (Seed and Rahman 1978), several analytical approximations and numerical models have been developed (Sumer and Fredsøe 2002; Jeng 2013). All of them are onedimensional 1-D models based on empirical data of pore pressure accumulation and apply to elastic soil behavior using the following governing equation:

$$
\frac{\partial \bar{p}_{s}^{*}}{\partial t}=c_{v}^{*} \frac{\partial^{2} \bar{p}_{s}^{*}}{\partial z^{2}}+f^{*}
$$

where $\bar{p}_{s}^{*}$ denotes the wave-induced residual pore pressure using a 1-D model and $c_{v}^{*}$ is the 
coefficient of consolidation, which is defined as follows:

$$
c_{v}^{*}=\frac{G K}{\gamma_{w}} \frac{2(1-\mu)}{(1-2 \mu)+(2-2 \mu) n G \beta_{s}} .
$$

In equation (16), the source term $\left(f^{*}\right)$ is expressed as follows (Seed and Rahman 1978; Sumer and Fredsøe 2002; Jeng 2013):

$$
f^{*}=\frac{\partial u_{g}}{\partial t}=\frac{\sigma_{0}^{\prime}}{T}\left[\frac{\left|\tilde{\tau}_{\text {max }}\right|}{\alpha_{r} \sigma_{0}^{\prime}}\right]^{-\frac{1}{\beta_{r}}},
$$

where $u_{g}$ is the generation of pore pressure (Seed and Rahman 1978), $\left|\tilde{\tau}_{\text {max }}\right|$ is the maximum amplitude of the oscillatory shear stress, obtained from the solution of the Biot equations (Hsu and Jeng 1994), and $\alpha_{r}$ and $\beta_{r}$ are obtained by the large-scale simple shear test data corresponding to the relative density $\left(D_{r}\right)$ of the soil as proposed by de Alba et al. (1976). The relative density, $D_{r}$, is defined as follows:

$$
D_{r}=\frac{e_{\max }-e}{e_{\max }-e_{\min }}
$$

where $e$ is the void ratio, and $e_{\max }$ and $e_{\min }$ are the maximum and minimum void ratios, respectively. The coefficients $\alpha_{r}$ and $\beta_{r}$ in equation (18) are defined from the following empirical expressions (Sumer et al. 2012):

$$
\alpha_{r}=0.34 D_{r}+0.084, \quad \beta_{r}=0.37 D_{r}-0.46 .
$$

The quantity $\sigma_{0}^{\prime}$ in equation (18) is the initial effective stress and is expressed as follows:

$$
\sigma_{0}^{\prime}=\frac{1+2 K_{0}}{3} \gamma^{\prime} z
$$

where $K_{0}$ is the coefficient of lateral earth pressure, and $\gamma^{\prime}$ is the submerged specific weight of the soil.

The above 1-D model for the wave-induced residual pore pressure can be solved with the 
initial boundary condition, $\bar{p}_{s}^{*}(z, 0)=0$ (Sumer and Fredsøe 2002; Jeng 2013).

\section{Residual soil response: New 2-D model}

In this study, the above 1-D model is re-derived to create a two-dimensional (2-D) as follows:

$$
\frac{\partial \bar{p}}{\partial t}=c_{\nu}\left(\frac{\partial^{2} \bar{p}}{\partial x^{2}}+\frac{\partial^{2} \bar{p}}{\partial z^{2}}\right)+f(x, z, t)
$$

where $c_{v}$ is the coefficient of consolidation based on the plain-strain, which is defined as follows:

$$
c_{v}=\frac{G K}{\gamma_{w}(1-2 \mu)}
$$

The source term $(f(x, z, t))$ for the new model is defined as follows:

$$
f(t)=\frac{\partial u_{g}}{\partial t}=\frac{\sigma_{0}^{\prime}}{T}\left[\frac{\left|\tilde{\tau}_{i n s}(x, z, t)\right|}{\alpha_{r} \sigma_{0}^{\prime}}\right]^{-\frac{1}{\beta_{r}}},
$$

where $\tilde{\tau}_{\text {ins }}(x, z, t)$ is the phase-resolved oscillatory shear stress.

To solve the 2-D governing equation (22) with the new source term, appropriate boundary conditions are applied, i.e., (a) at the seabed surface $(z=0)$, the residual pore pressure is assumed to be zero $(\bar{p}=0)$; (b) at the bottom of the porous seabed with finite thickness $(z=-h)$, $\frac{\partial \bar{p}_{s}}{\partial z}=0$ at $z=-h$ ); and (c) lateral boundary conditions are assumed to be zero flux. The seabed model is developed using the COMSOL Multiphysics environment (COMSOL 2010) with the dynamic wave pressures obtained from the wave model (COBRAS).

This model reflects the effects of instant oscillatory shear stresses on the pore pressure buildup, which will become a time-dependent function, However, the present model doesn't considers the effects of residual pore pressures on the evolutions of oscillatory shear stresses and shear strains. This is the limitation of the model. 


\section{Integration of wave and seabed models}

The flow field, including the non-linear water elevation, the velocity field and the wave pressures, are determined from COBRAS. Then we extract the wave pressure along seabed surface from the wave model. This wave pressure is imposed as the boundary condition at the seabed surface of the seabed model. The oscillatory seabed response, including pore water pressure, soil displacement and effective shear stress, is found by solving the Biot consolidation equations using a finite element method. The oscillatory shear stresses are included in the source term and the residual soil response are determined using equation (22).

COBRAS, used as the wave model, has the ability to predict non-linear waves propagating over a sloping seabed (including tsunamis and breaking waves) and the interactions between waves and marine structures, such as breakwaters and pipelines. Even though we only present the results for the case of progressive waves and satnding waves, the VARANS model (COBRAS) is integrated with the seabed modelsuch that the entire model. This study is part of the long-term development of the numerical model for fluid-soil-structure interactions, in which the strctures will be included in the next project.

\section{RESULTS AND DISCUSSION}

\section{Validation of the present model}

To validate the present model, we performed the following comparisons between the present model and the previous analytical solutions and experimental data.

- Comparison with 1-D laboratory experiments (Liu and Jeng 2013) for the oscillatory pore pressure under progressive waves.

- Comparison withwave flume tests (Sumer et al. 2012) for residual pore pressure under progressive waves.

- Comparison withwave flume tests (Tsai and Lee 1995) for oscillatory pore pressure under standing waves. 
- Comparison with wave flume tests (Kirca et al. 2013) for residual pore pressure under standing waves.

In the first validation, we compare the results of our oscillatory pore pressure with the previous analytical solutions (Hsu and Jeng 1994) and laboratory experiments (Liu and Jeng 2013). Based on Biot's poro-elastic theory, Hsu and Jeng (1994) analytically investigated the waveinduced soil response in an isotropic seabed of finite thickness. This analytical solution has been widely used for the validation of wave-induced oscillatory pore pressure in a porous seabed without structures in the literature (Sumer and Fredsøe 2002). Recently, Liu and Jeng (2013) conducted a series of 1-D laboratory experiments to investigate the vertical profile of pore pressure distributions in marine sediments. The 1-D facility used for their experiments was set up with a vertical cylinder, a $1.8 \mathrm{~m}$ soil layer and $0.2 \mathrm{~m}$ of water above the deposit. This set up is an improvement on the one originally designed by Zen and Yamazaki (1990). Unlike Zen and Yamazaki (1990), an additional static load was applied on the dynamic load. This allows the facility to simulate the case of large waves, better simulating the natural ocean environment (Liu and Jeng 2013). The numerical results for the maximum vertical oscillatory pore pressure $\left(\tilde{p} / p_{0}\right)$ versus relative soil depth $(z / h)$ are shown in Figure 2. As shown in the figure, the present model agrees overall with both the analytical solution and the experimental data. In the comparison, we also include the comparisons between the present model and previous analytical solution for effective normal stresses and shear stresses. Overall, the present model also agrees with the previous analytical solution (Hsu and Jeng 1994).

Sumer et al. (2012) conducted an experimental study for the pore pressure accumulation and liquefaction in marine soils under progressive waves. The experimental data reported inSumer et al. (2012) are used here to further verify the residual component of the present numerical model. Both the numerical results from the "2-D instant model", the "2-D maximum model" and the 1-D analytical solutions developed by Sumer et al. (2012), are included in this comparison. Note that, the model in which the maximum shear stress over the wave period in the source term are used to simulate the pore pressure accumulation is called the "2-D maximum model". 
The maximum shear stress in the "2-D maximum model" is actually a 1-D shear stress because it is independent of the $x$ - direction, similar to the previous research (Sumer and Fredsøe 2002; Jeng 2013). The model in which the phase-resolved oscillatory shear stress is used as the source of pore pressure accumulation is called the "2-D instant model". The input data are tabulated in Table 1 and the numerical comparisons are presented in Figure 3. As shown in the figure, there are not significant differences for the wave-induced pore pressure accumulation between the "2-D maximum model" and the 1D model (Sumer et al. 2012). For the case in which the phase-resolved shear stresses over the wave period are used as the source of pore pressure accumulation ("2-D instant model"), the residual pore pressures are relatively small during the entire build-up process. However, the overall trend of the residual pore pressure of the present "2-D instant model" captures the experimental data well. This comparison validates our model and demonstrates the significant improvement of the prediction of the wave-induced residual pore pressures in marine sediments with the new definition of the source term applied in our 2-D model.

In the third comparison, we compare the present results with the previous wave flume tests (Tsai and Lee 1995) for standing wave-induced oscillatory pore pressures in a porous seabed. In the experiments, the wave period $(T)=1.5 \mathrm{sec}$, the wave height $(H)=5.1 \mathrm{~cm}$, the water depth $(d)=0.45 \mathrm{~m}$, the soil permeability $(K)=1.2 \times 10^{-4} \mathrm{~m} / \mathrm{s}$, the porosity $\left(n_{e}\right)=0.38$, the shear modulus $(G)=2.64 \times 10^{7} \mathrm{~N} / \mathrm{m}^{2}$, the seabed thickness $(h)=0.5 \mathrm{~m}$, Poisson's ratio $\left(\mu_{s}\right)=$ 0.29 , and the degree of saturation $(S)=0.98$. As shown in Figure 4, overall the predictions of the model agree well with the experimental data.

In the fourth validation, we compared the model with the recent experimental data (Kirca et al. 2013) for the standing wave-induced residual pore pressure. The soil conditions for the experiments were the same as the second validation (Sumer et al. 2012) and the wave period (T) $=1.09 \mathrm{~s}$, the wave height $(H)=10.2 \mathrm{~cm}$ and the water depth $(d)=0.3 \mathrm{~m}$. As shown in Figure 5, overall the model catches the trend of the experimental data for the standing wave-induced residual pore pressures. 
In Kirca et al. (2013) experiments, the soil pit was divided into two by sealed additional plate. However, in the present numerical model, the configuration of the soil is slightly different from the experiments. This is the reason why the prediction of pore pressures by the model can only catch the trend, compared with the experimental results. Furthmore, in the model, the wave reflection was generated by a vertical wall placed at the end of the computing domain. Furthermore, the vertical wall was extended downward into the seabed. This doesn't allow the pressure flux go through.

Note that the above validations are based on works available in the literature. To the authors' best knowledge, the experiments conducted by Kirca et al. (2013) was the only one provided synchronized time series of residual pore pressure measured at different location in the $x$-direction. This model furtehr confirms with their experimental results (Kirca et al. 2013)

\section{Effect of nonlinear component of wave loading}

The flow field in most of the previous studies (Sumer and Fredsøe 2002; Jeng 2013) are limited to analytical linear progressive wave solutions. In real ocean environments, ocean waves, especially in the shallow water zone, are always characterized as non-linear. Therefore, it is necessary to examine the effect of the nonlinear component of the wave loading in the seabed response, including both the oscillatory pore pressure and the residual pore pressure. With the input parameters shown in Table 2, the distributions of the wave-induced pore pressure under different components of wave loading versus wave cycle areshown in Figure 6(a). The total pore pressure $\tilde{p}+\bar{p}$ (blue lines) and residual pore pressure $\bar{p}$ (red lines) are illustrated in the figure. As shown in the figure, the model simulates the phenomenon of wave-induced residual pore pressure. The model results show that from $t=0$, when the residual pore pressure is equal to zero, the peak value of the oscillatory pore pressure for a case under a nonlinear wave loading is higher than that for the case under a linear wave loads. This is the reason why the pore pressure for a case under a nonlinear wave loading accumulates. The regions between the two dashed lines in Figures 6(a) and 6(b) were selected for enlargement in Figure 6(c), and a more definite comparison of the residual pore pressure between these two components of wave loads 
are shown in Figure 6(d). As shown in the figure, the pore pressure accumulates faster for the case under a nonlinear wave loading.

\section{Liquefaction zone with the present 2-D model}

Although residual liquefaction caused by progressive waves has been extensively investigated, studies of standing wave-induced liquefaction are relatively rare. Sassa and Sekiguchi (1999) carried out a series of centrifuge wave tests to investigate seabed liquefaction under standing waves, in which the antinode of the standing wave is formed in the middle of their sediment pit. In this study, the standing waves are obtained in front of an impervious vertical wall by solving the VARANS equations with a finite difference method. The turbulence fluctuations between the wave and the structure are simulated using the volume-averaged $k-\epsilon$ model. The wave parameters are shown in Table 2. In this example, the antinode of the standing wave is formed in the middle of the simulation domain of the integreated model, which is located at $x$ $=744 \mathrm{~m}$ with wavelength of approximately $112 \mathrm{~m}$. The standing wave is used to analyze of the development of the liquefaction zone and the pore pressure accumulation.

It is well-known that liquefaction occurs when the excess pore pressure reaches the initial effective stress, i.e., $\bar{p}_{s}=\sigma_{0}^{\prime}$. The source term for the residual pore pressure generation is 2-D and time-dependent function in the present model. This feature directly affects the pattern of the liquefaction zone. Using the input data in Table 2, Figure 7(a) shows the resulting variations of wave-induced residual liquefaction zones versus the wave cycle $(t / T)$ for various types of wave loads. As shown in the figure, the liquefaction zone under progressive waves occurs as a 2-D pattern during the first wave period after liquefaction $(t / T=90$ in this example). The reason there is a 2-D liquefaction zone in the first liquefaction wave period may be from the 2-D phase-resolved shear stress used as the source of the pore pressure. The region where the 2-D pattern occurs is related to the initial incidence of the wave phases. As the progressive wave loading continues, the nature of the liquefaction zone chnages from 2-D pattern to 1-D pattern after one wave period. The 1-D pattern travels with the wave and reaches a constant value after several wave cycles. 
For the case of the standing waves, as shwon in Figure 7(b), the liquefaction zone will occur initially in the region where the shear strains are most significant, then this liquefied zone extends laterally and vertically. Finally even the soil at the antinode section will be liquefied after certain wave cycles. This phenomenon coincide well with what has been discussed by Sassa and Sekiguchi (2001).

In addition to the development of liquefaction zone, it is necessary to investigate the residual pore pressure along $\mathrm{x}$-direction with the present model. The distributions of residual pore pressure along $x$ - direction at three typical locations under different types of wave loads estimated by the 2-D model are presented in Figures 7(c) \& 7(d). The model esults show that, there are only minor differences in the pore pressure accumulation along $x$-direction under the effect of progressive waves. Because the liquefaction occurs at $t / T=90$ in this example, a more definitive comparison of pore pressure accumulation along the $x$-direction between $t / T=80$ and $t / T=100$ is shown in Figure 7(e). The results show that the pore pressure in the soil during the initial 2-D liquefaction pattern, i.e., at $(x, z)=(710,-0.5) \&(x, z)=(770,-0.5)$, accumulate faster compared with that at location $(x, z)=(740,-0.5)$. This phenomenonis likely because the difference between the residual pore pressure along $x$-direction under progressive waves may be related to the difference of the shear strains along the $x$-direction induced by the initial incidence of the wave phase. After which, every $x$ section will experience the same progressive wave loading as the wave progresses; therefore, after a long loading time, the difference in pore pressure during the first wave cycle can be neglected. However, a strong $x$ - dependence is observed for the case of the standing waves, where the pore pressure can accumulate to a much larger value in the location where the wave-induced shear strains are the highest, compared with the shear strain in the antinode section.

\section{Progressive liquefaction}

Sassa et al. (2001) developed an elasto-plastic constitutive model for the wave-induced liquefaction in sand beds with infinite thickness in which the source term was related to the rate of plastic volumetric deformation $\partial \epsilon^{p} / \partial t$, while the stress ratio $\tau / \sigma_{z 0}^{\prime}$ was still estimated 
by the poro-elastic solutions considering the presence of liquefaction front. The maximum liquefaction depth $\left(z_{L}\right)$ increases as time increases, approaching a constant. This behavior is similar to the behavior of the more sophisticated model previously developed for progressive liquefaction (Sassa et al. 2001). The comparison of the distribution of maximum liquefaction depths $\left(z_{L}\right)$ versus time $(t)$ between Sassa's model (Sassa et al. 2001) and the present 2-D instant model are presented in Figure 8. The input data for this comparison are shown in Table 3. The results in Figure 8 show that the maximum liquefication depth gradually increases and approaches a constant with sufficient time. Although there is a difference in the growth trends between Sassa's model and the present model, the final liquefaction depth predicted by the present instant model matches fairly well with the results predicted by Sassa's elasto-plastic model (Sassa et al. 2001). The stress axes rotation are neglected in the present poro-elastic model as a first approximation, which have been proven to be particularly important in the evaluation of the wave-induced residual liquefaction (Sassa and Sekiguchi 2001). This example is only used to demonstrate that the present 2-D model is capable in the first-hand prediction of the development of progressive liquefaction. For a dteailed investigation, the reader still need to refer to Sassa et al. (2001) model.

\section{Effects of the wave characteristics on the progression of the liquefaction depth}

It is well-known that wave characteristics play an important role in the evaluation of the wave-induced seabed response (Jeng 2013). Among these, the water depth, the wave period and the wave height are three key wave parameters considered in the present study. Figure 9(a) illustrates the effect of the wave height on the progression of the liquefaction depth in time. As shown in the figure, the maximum liquefaction depth increases faster and accumulate to a larger value under larger wave loadings.

In general, a decrease in water depth $(d)$ results in a decrease in the wave length $(L)$. When the wave height $(H)$ is the same, a decrease in thewavelength will result in a large wave steepness $(H / L)$ and hence a wave that is closer to breaking, i.e., the large wave condition. Therefore, a decrease of the value $(d)$ from $20 \mathrm{~m}$ to $18 \mathrm{~m}$ causes the final liquefaction depth to more than 
halve, as shown by the data in Figure 9(b).

Basically, wave length increases as the wave period increases. The shear strains from the pressure also increase as the wave length increases. As a result, the pore pressure should accumulate to a large value. However, wave flume tests have shown (Sumer et al. 1999; Sumer et al. 2012) that the pore pressure accumulation is not only related to the shear stress ratio $\left(\tau \sigma_{z}^{\prime}\right)$, but also to the period of the cyclic loadings. Therefore, the effect of the wave period on the wave-induced pore pressure accumulation is also examined. As shown in Figure 9(c), the liquefaction depth accumulates more readily in the case with a small wave period. This occurs because the pore pressure and the energy have less time to drain out in the short wave period.

Based on the results presented in Figure 9, it can be concluded that the liquefaction depth increases more easily to accumulate under conditions of: (1) larger amplitude waves, (2) small wave periods and (3) shallow water.

\section{Effects of the soil properties on the progression of the liquefaction depth}

In addition to the wave parameters, soil properties are also important for the wave-induced pore pressure in marine sediments (Sumer and Fredsøe 2002; Jeng 2013). The buildup empirical coefficient $\alpha_{r}$ and $\beta_{r}$ are related to the relative density $\left(D_{r}\right)$, while the dissipation rate of the pore pressure are related to the soil permeability $(K)$. Thus, we further examined the effects of $K$ (soil permeability) and $D_{r}$ (relative density) on the build-up pattern. The seabed characteristics are Poisson's ratio $\mu=0.35$, the degree of saturation $S_{r}=1$, and the seabed porosity $n=0.425$. Figures 9(d) and 9(e) illustrates the time histories of the progression of the liquefaction depth in the soil with different permeability $(K)$ and relative density $\left(D_{r}\right)$. As shown in Figures $9(\mathrm{~d})$ and 9(e), soils with a low permeability and low relative density increase liquefaction deeper because a high permeability results in a high dissipation rate, which makes the pore pressure more difficult to accumulate. In addition, a decrease in the value of $D_{r}$ from 0.4 to 0.3 will cause the final liquefaction depth to more than halve, and less time for the soil with a higher permeability to reach its final liquefaction depth. 


\section{CONCLUSIONS}

In this study, with the source term is defined as 2-D and time-dependent function, a new 2-D model for pore pressure accumulation in marine sediment is proposed. The following conclusions are based on the numerical results:

1. Both the oscillatory component and the residual mechanism are validated against experimental data (Sumer et al. 2012; Liu and Jeng 2013). The comparison indicates that the present "2-D instant model" is reliable for the prediction of the wave-induced residual pore pressures in marine sediments with the new definition of the source term.

2. The residual pore pressure in the soil under nonlinear components of wave loads is more likely to accumulate to a large value compared with that under linear wave loads, because the magnitude of wave-induced shear strains for the case under nonlinear components of wave loads is larger than that under linear wave loads.

3. In the wave field numerical modelling, standing waves were obtained in front of a impermeable seawall, in which the turbulence fluctuations induced by the wave-structure interaction are simulated using the volume-averaged $k-\epsilon$ model. The antinode of the standing wave in the integrated model is formed in the middle of the simulation domain.

4. For the case of progressive wave loads, the liquefaction zone occurs as 2-D pattern during the first liquefaction wave period $(t / T=90$ in the example). The region of this initial 2-D liquefaction zone is related to the initial incidence of the wave phase. The 2-D pattern changes from 2-D to 1-D in one wave period. This 1-D pattern travels progressively with the wave, and reach a constant value after several wave cycles. For the case of standing wave loads, a 2-D liquefaction zone will occur first in the region where the shear strains are highest. The 2-D zone then expands laterally and vertically to neighbouring points. The soil in the antinode section will eventually undergoing liquefies.

5. There is no significant difference in the pore pressure accumulation in the $x$ - direction for the case under progressive wave loads. However, there is a strong $x$ - dependence in 
pore pressure accumulation for the case of standing wave loads. It takes a much longer time for the soil in the antinode section to liquefy compared to the soil in other sections.

6. It is found that there is significant difference of the progress of liquefaction depth versus time between the present model and Sassa's model (Sassa et al. 2001); however, the final liquefaction depths are nearly the same. This indicates that our present 2-D elastic model is able to predict the maximum progressive liquefaction depth. Parametric studies indicate that, the seabed with lower permeability and relative density under a higher energy wave with a short wave period (i.e., larger wave, short wave period, shallow water) is more likely to be liquefied.

Note that this paper presented a new 2-D model for the wave-induced accumulation of por pressures in marine sediment. This model can be further applied to other cases with marine infrastructures such as offshore pipelines (Zhao et al. 2014).

\section{ACKNOWLEDGEMENTS}

This study was partially funded by the EU commission through the FP-7 project "innovative Multi-purpose Offshore Platforms: Planning Design and Operation” (MERMAID, G.A.No. 288710). We gratefully acknowledge the support of the Griffith University eResearch Services team and the use of the High Performance Computing Cluster "Gowonda" to complete this research.

\section{REFERENCES}

Biot, M. A. (1941). "General theory of three-dimensional consolidation.” Journal of Applied Physics, 26(2), 155-164.

Cheng, L., Sumer, B. M., and Fredsøe, J. (2001). "Solution of pore pressure build up due to progressive waves." International Journal for Numerical and Analytical Methods in Geomechanics, 25, 885-907.

COMSOL (2010). COMSOL Multiphysics, 3rd Edition. 
de Alba, P., Seed, H. B., and Chan, C. K. (1976). "Sand liquefaction in large-scale simple shear tests." Journal of Geotechnical Division, ASCE, 102, 909-928.

Hsu, J. R. C. and Jeng, D.-S. (1994). "Wave-induced soil response in an unsaturated anisotropic seabed of finite thickness." International Journal for Numerical and Analytical Methods in Geomechanics, 18(11), 785-807.

Jeng, D.-S. (2013). Porous Models for Wave-seabed Interactions. Springer.

Jeng, D.-S., Seymour, B. R., and Li, J. (2007). "A new approximation for pore pressure accumulation in marine sediment due to water wave." International Journal for Numerical and Analytical Methods in Geomechanics, 31(1), 53-69.

Kirca, V. S. O., Sumer, B. M., and Fredsøe, J. (2013). "Residual liquefaction of seabed under standing waves." Journal of Waterway, Port, Coastal and Ocean Division, ASCE, 139, 489501.

Lin, P. and Liu, P. L.-F. (1999). "Internal wave-maker for Navier-Stokes equations models." Journal of Waterway, Port, Coastal, and Ocean Engineering, ASCE, 125(4), 207-215.

Liu, B. and Jeng, D.-S. (2013). "Laboratory study for pore pressure in sandy bed under wave loading." The 23rd (2013) International Offshore and Polar Engineering Conference (ISOPE2013), Anchorage, Alaska, USA 2013, 1432-1437.

Liu, Z., Jeng, D.-S., Chan, A. H., and Luan, M. T. (2009). "Wave-induced progressive liquefaction in a poro-elastoplastic seabed: A two-layered model." International Journal for Numerical and Analytical Methods in Geomechanics, 33(5), 591-610.

McDougal, W. G., Tsai, Y. T., Liu, P. L.-F., and Clukey, E. C. (1989). "Wave-induced pore water pressure accumulation in marine soils." Journal of Offshore Mechanics and Arctic Engineering, ASME, 111(1), 1-11.

Rodi, W. (1980). "Turbulence models and their application in hydraulics-state-of-the-art review." IAHR Publication.

Sassa, S. and Sekiguchi, H. (1999). "Wave-induced liquefaction of beds of sand in a centrifuge." Géotechnique, 49(5), 621-638. 
Sassa, S. and Sekiguchi, H. (2001). "Analysis of wave-induced liquefaction of sand beds." Géotechnique, 51(2), 115-126.

Sassa, S., Sekiguchi, H., and Miyamoto, J. (2001). "Analysis of progressive liquefaction as a moving-boundary problem." Géotechnique, 51(10), 847-857.

Seed, H. B. and Rahman, M. S. (1978). "Wave-induced pore pressure in relation to ocean floor stability of cohesionless soils.” Marine Geotechnology, 3(2), 123-150.

Sekiguchi, H., Kita, K., and Okamoto, O. (1995). "Response of poro-elastoplastic beds to standing waves." , 35(3), 31-42.

Sumer, B. M. and Fredsøe, J. (2002). The Mechanism of Scour in the Marine Environment. World Scientific, New Jersey.

Sumer, B. M. (2014). Liquefaction around marine structures. World Scientific, New Jersey.

Sumer, B. M., Fredsøe, J., Christensen, S., and Lind, M. T. (1999). "Sinking/floatation of pipelines and other objects in liquefied soil under waves." Coastal Engineering, 38, 53-90.

Sumer, B. M., Kirca, V. S. O., and Fredsøe, J. (2012). "Experimental validation of a mathematical model for seabed liquefaction under waves." International Journal of Offshore and Polar Engineering, 22, 133-141.

Tsai, C. P. and Lee, T. L. (1995). "Standing wave induced pore pressures in a porous seabed." Ocean Engineering, 22(6), 505-517.

Tzang, S. Y. (1998). "Unfluidized soil responses of a silty seabed to monochromatic waves." Coastal Engineering, 35(4), 283-301.

Zen, K. and Yamazaki, H. (1990). "Mechanism of wave-induced liquefaction and densification in seabed." Soils and Foundations, 30(4), 90-104.

Zhao, H., Jeng, D.-S., Guo, Z., and Zhang, J. S. (2014). “Two-dimensional model for pore pressure accumulations in the vicinity of a buried pipeline." Journal of Offshore Mechanics and Arctic Engineering, ASME, in press. 
1 Soil properties and wave characteristics used in the validations. . . . . . . . . . 24

511

2 Input data for numerical examples. 25

Soil and wave characteristics for verification with Sassa's model. . . . . . . . . 26 
TABLE 1. Soil properties and wave characteristics used in the validations.

\begin{tabular}{ll}
\hline Seabed characteristics & Value \\
\hline Soil porosity $\left(n_{e}\right)$ & 0.51 \\
Poisson's ratio $(\mu)$ & 0.29 \\
Shear modulus $(G)$ & $1.92 \times 10^{6}\left(\mathrm{~N} / \mathrm{m}^{2}\right)$ \\
Soil permeability $(K)$ & $1.5 \times 10^{-5}(\mathrm{~m} / \mathrm{s})$ \\
Coefficient of lateral earth pressure $\left(K_{0}\right)$ & 0.42 \\
Submerged specific weight of soil $\left(\gamma^{\prime}\right)$ & $8.14\left(\mathrm{kN} / \mathrm{m}^{3}\right)$ \\
Degree of saturation $(S)$ & 1 \\
Relative density $\left(D_{r}\right)$ & 0.28 \\
Thickness $(h)$ & $0.4(\mathrm{~m})$ \\
\hline Wave characteristics & Value \\
\hline Wave period $(T)$ & $1.6(\mathrm{~s})$ \\
Wave height $(H)$ & $0.18(\mathrm{~m})$ \\
Water depth $(d)$ & $0.55(\mathrm{~m})$ \\
\hline
\end{tabular}


TABLE 2. Input data for numerical examples.

\begin{tabular}{ll}
\hline Seabed characteristics & Value \\
\hline Soil porosity $\left(n_{e}\right)$ & 0.425 \\
Poisson's ratio $(\mu)$ & 0.35 \\
Shear modulus $(G)$ & $5 \times 10^{6}\left(\mathrm{~N} / \mathrm{m}^{2}\right)$ \\
Soil permeability $(K)$ & $10^{-4}(\mathrm{~m} / \mathrm{s})$ \\
Coefficient of lateral earth pressure $\left(K_{0}\right)$ & 0.41 \\
Submerged specific weight of soil $\left(\gamma^{\prime}\right)$ & $10.73\left(\mathrm{kN} / \mathrm{m}^{3}\right)$ \\
Degree of saturation $(S)$ & 1 \\
Relative density $\left(D_{r}\right)$ & 0.2 \\
Thickness $(h)$ & $50(\mathrm{~m})$ \\
\hline Wave characteristics & Value \\
\hline Wave period $(T)$ & $10(\mathrm{~s})$ \\
Wave height $(H)$ & $5(\mathrm{~m})$ \\
Water depth $(d)$ & $16(\mathrm{~m})$ \\
\hline
\end{tabular}


TABLE 3. Soil and wave characteristics for verification with Sassa's model.

\begin{tabular}{ll}
\hline Seabed characteristics & Value \\
\hline Soil porosity $\left(n_{e}\right)$ & 0.425 \\
Poisson's ratio $(\mu)$ & 0.35 \\
Shear modulus $(G)$ & $5 \times 10^{6}\left(\mathrm{~N} / \mathrm{m}^{2}\right)$ \\
Soil permeability $(K)$ & $1.5 \times 10^{-4}(\mathrm{~m} / \mathrm{s})$ \\
Coefficient of lateral earth pressure $\left(K_{0}\right)$ & 0.41 \\
Submerged specific weight of soil $\left(\gamma^{\prime}\right)$ & $10.73\left(\mathrm{kN} / \mathrm{m}^{3}\right)$ \\
Degree of saturation $(S)$ & 1 \\
Relative density $\left(D_{r}\right)$ & 0.27 \\
\hline Wave characteristics & Value \\
\hline Wave period $(T)$ & $10(\mathrm{~s})$ \\
Wave height $(H)$ & $6.5(\mathrm{~m})$ \\
Water depth $(d)$ & $20(\mathrm{~m})$ \\
\hline
\end{tabular}




\section{List of Figures}

1 Sketch of wave-seabed interaction. . . . . . . . . . . . . . . 28

2 Vertical distribution of maximum wave-induced oscillatory pore pressure versus relative soil depth for comparison between the present 2-D model (solid lines) with the1-D experimental results (symbols, Liu and Jeng (2013)) and the analytical solution (dashed lines, Hsu and Jeng (1994)). . . . . . . . . . . . .

3 Comparison of the experimental data (Sumer et al., 2012) and the present model results: (a) time histories of the residual pore pressure and (b) vertical distributions of $\bar{p}_{s}$ for different times. . . . . . . . . . . . . . . . . . 30

4 The comparison of the standing wave induced oscillatory pore pressure at the nine points in the sand bed between the experimental data (Tsai and Lee, 1995) and the numerical results. . . . . . . . . . . . . . 31

5 Comparison of the experimental data (Kirca et al., 2013) and the present model results for the case with standing waves. . . . . . . . . . . . . . 32

6 Distribution of the wave-induced pore pressure versus the wave cycle $(t / T)$ under different types of wave loads: (a) Linear wave loads; (b) Nonlinear wave loads; (c) Enlarge comparison; and (d) Comparison of residual pore pressure.

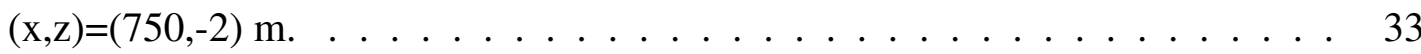

7 Tme histories of the development of the liquefaction zone and pore pressure accumulations along the $x$-direction under different types of waves (a) and (b) : liquefaction zones at different time, (c) and (d): pore pressure build up at three points; and (e) enclarged section of part (c) . . . . . . . . . . . . . . . . . 34

8 Comparison of the progression of thewave-induced liquefaction zone versus time between Sassa's model and the present model. . . . . . . . . . . . . . 35

9 Parametric studies for progress of wave-induced liquefied zone versus time for various (a)-(c) wave and (d)-(e) soil charcateristics. . . . . . . . . . . . . . 36 


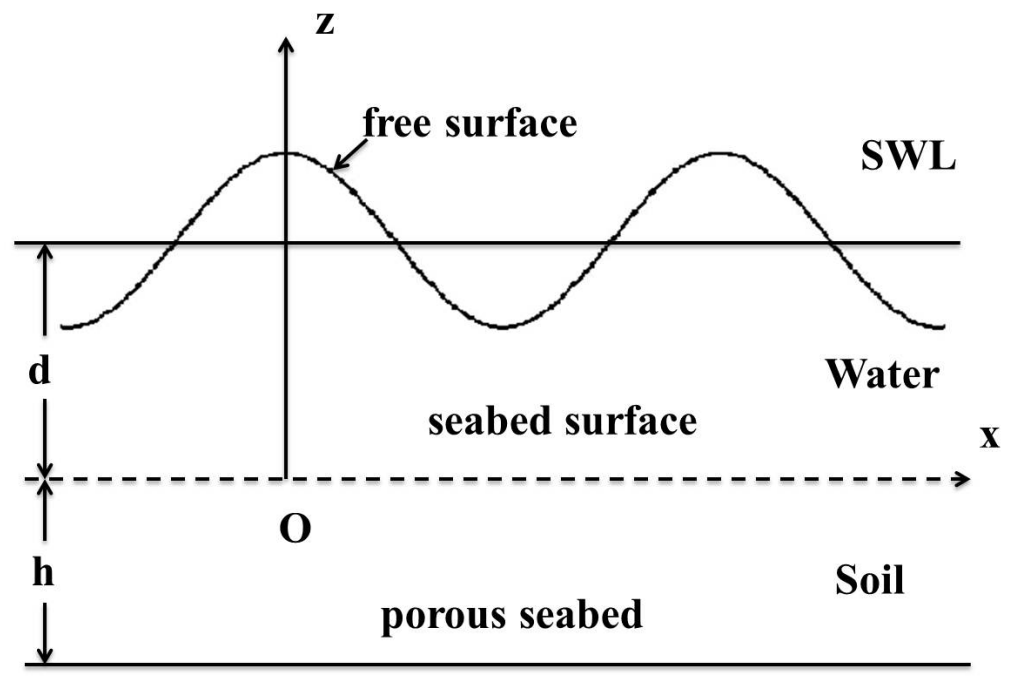

rigid impermeable bottom

FIG. 1. Sketch of wave-seabed interaction. 


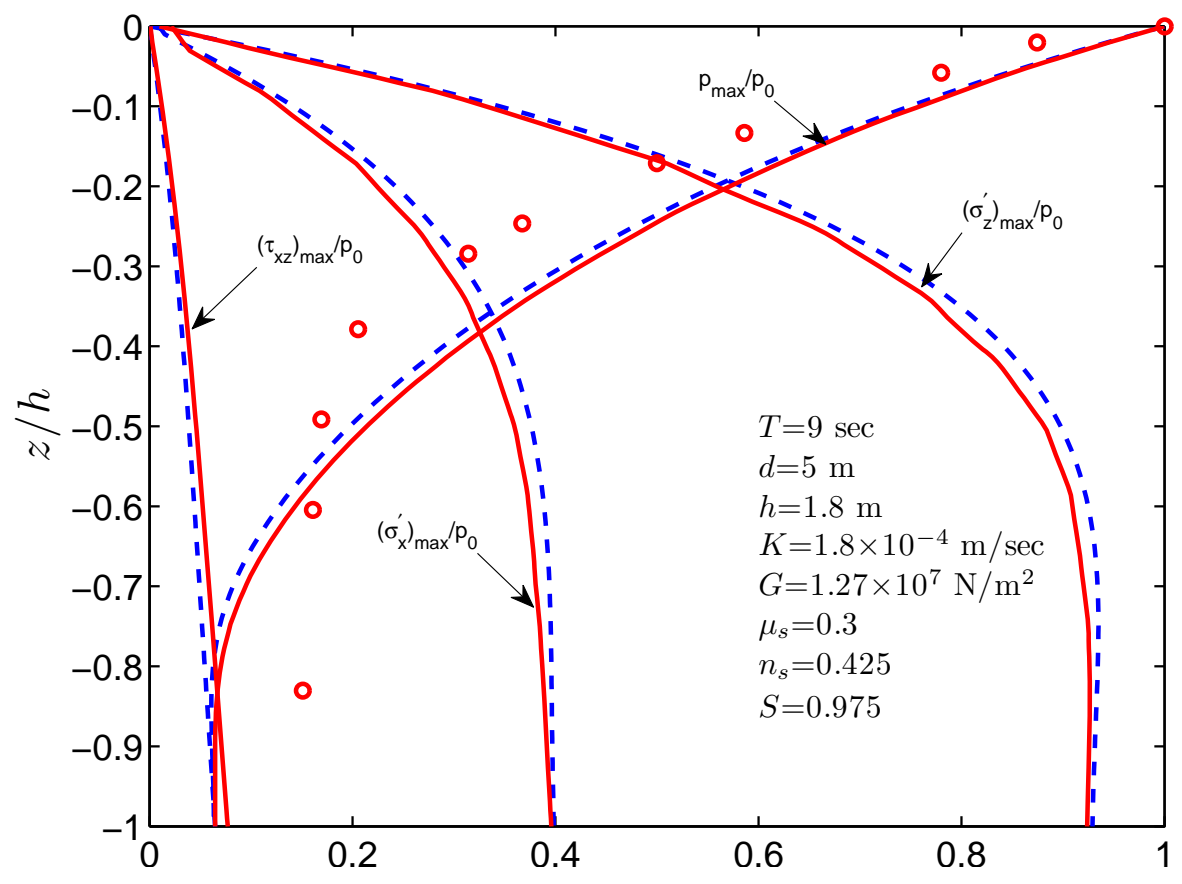

FIG. 2. Vertical distribution of maximum wave-induced oscillatory pore pressure versus relative soil depth for comparison between the present 2-D model (solid lines) with the1-D experimental results (symbols, Liu and Jeng (2013)) and the analytical solution (dashed lines, Hsu and Jeng (1994)). 


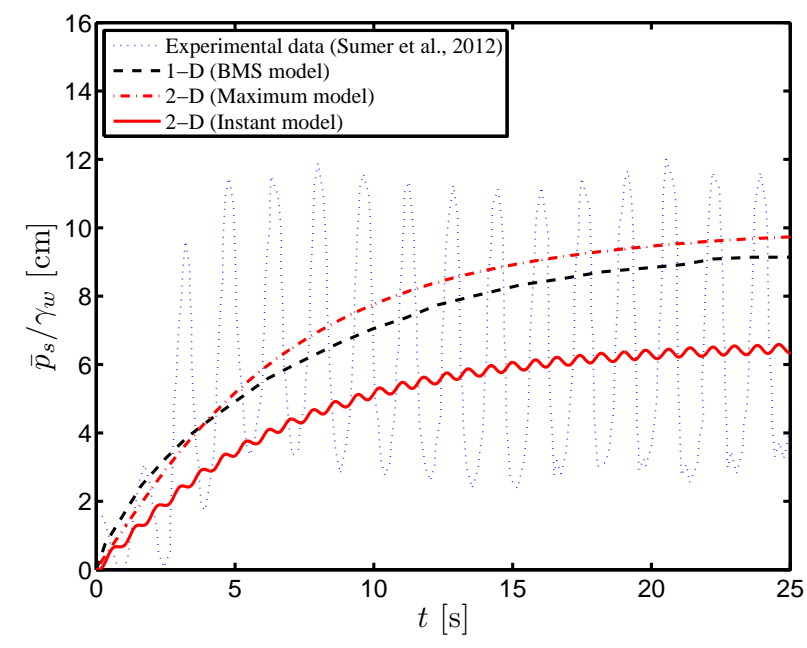

(a) $(x, z)=(0,-0.085) \mathrm{m}$

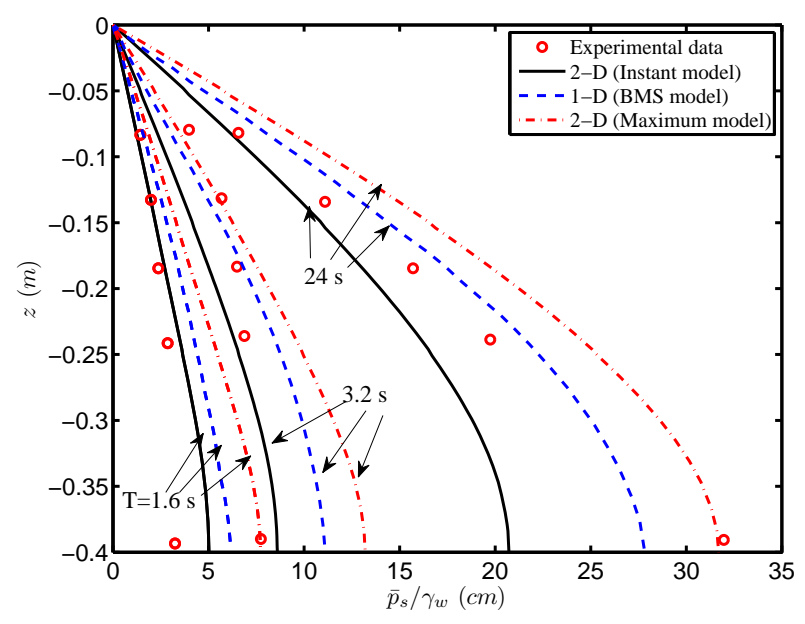

(b) $\mathrm{x}=0 \mathrm{~m}$

FIG. 3. Comparison of the experimental data (Sumer et al., 2012) and the present model results: (a) time histories of the residual pore pressure and (b) vertical distributions of $\bar{p}_{s}$ for different times. 

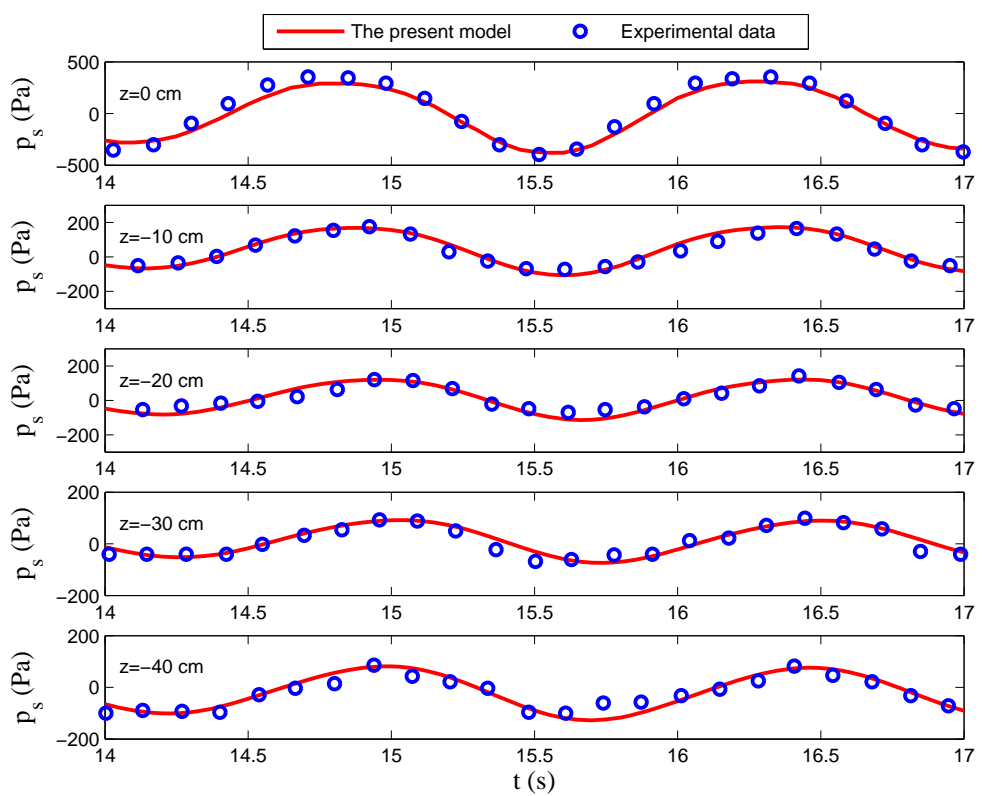

FIG. 4. The comparison of the standing wave induced oscillatory pore pressure at the nine points in the sand bed between the experimental data (Tsai and Lee, 1995) and the numerical results. 


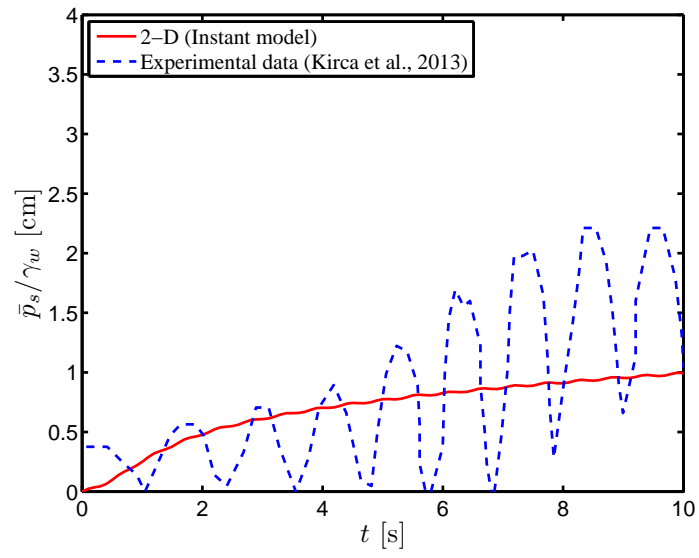

(a) $(x, z)=(0.585,-0.07) \mathrm{m}$

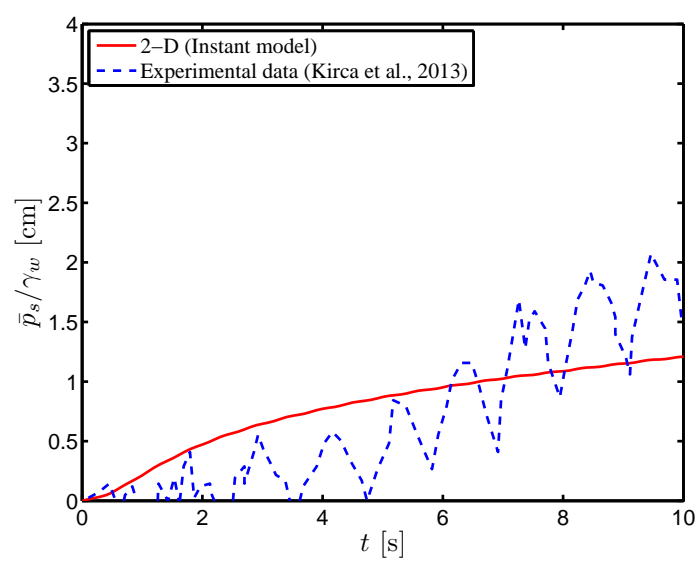

(b) $(\mathrm{x}, \mathrm{z})=(0.585,-0.135) \mathrm{m}$

FIG. 5. Comparison of the experimental data (Kirca et al., 2013) and the present model results for the case with standing waves. 


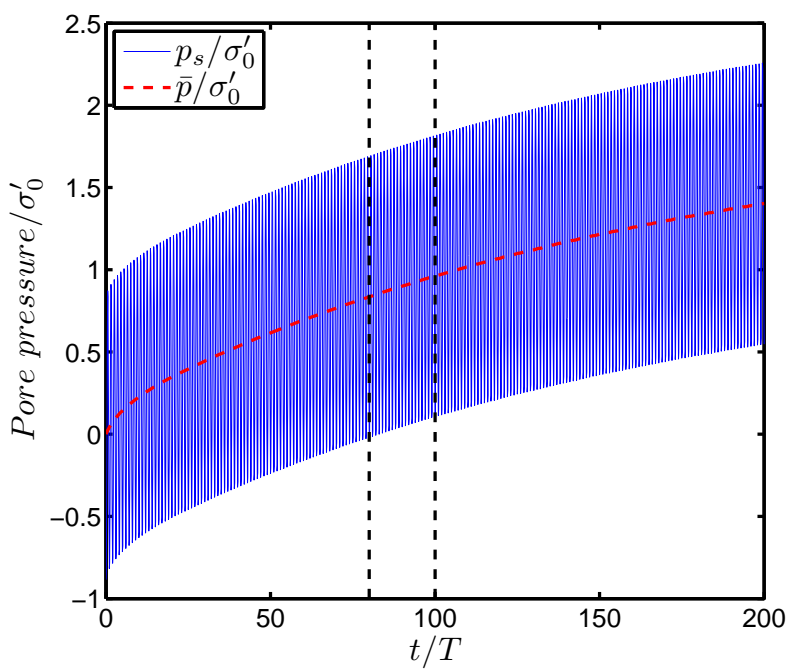

(a)

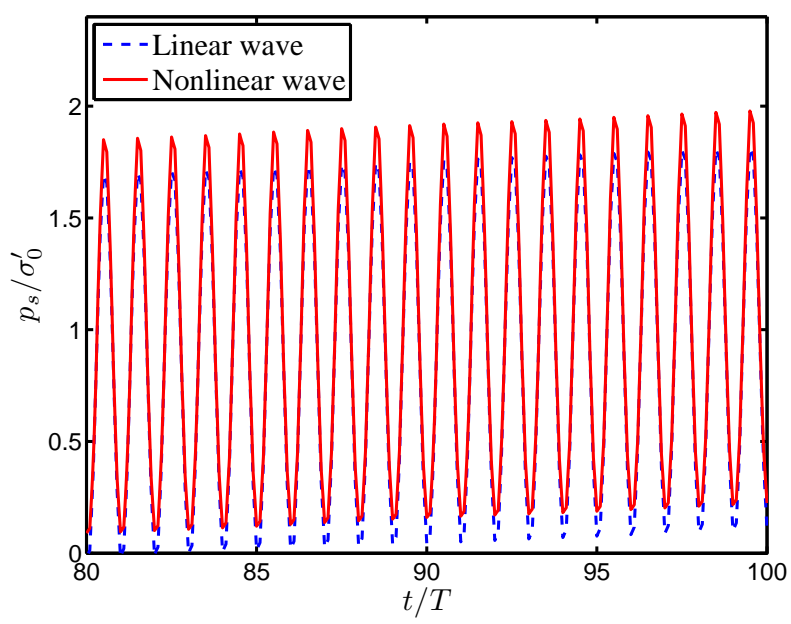

(c)

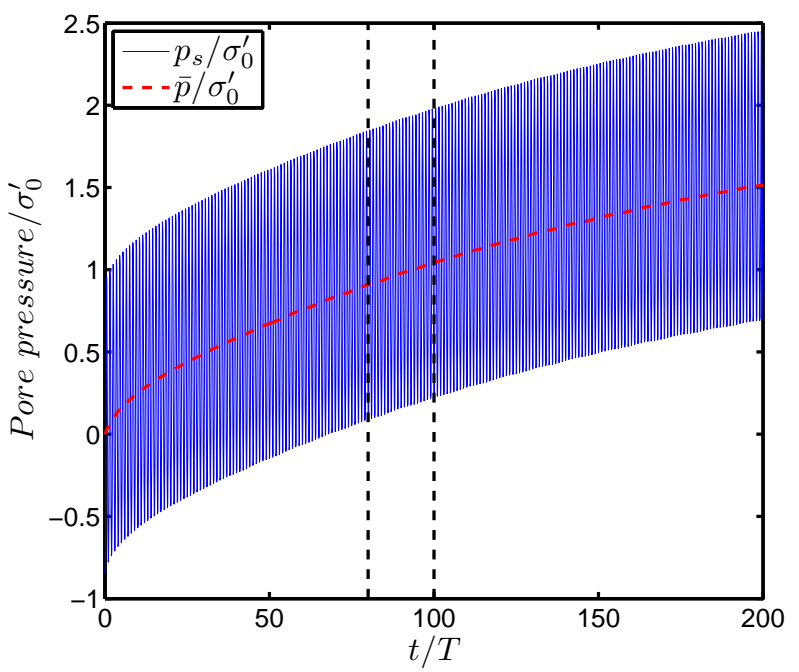

(b)

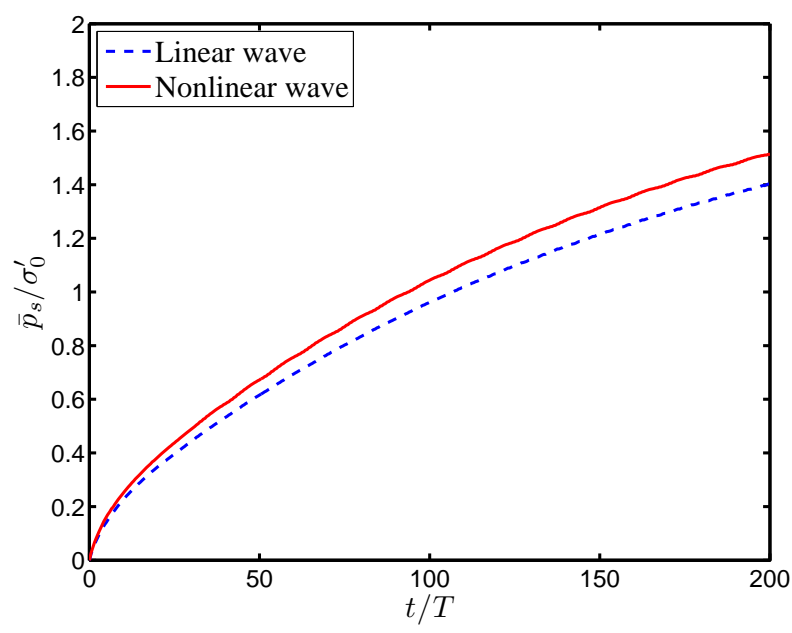

(d)

FIG. 6. Distribution of the wave-induced pore pressure versus the wave cycle $(t / T)$ under different types of wave loads: (a) Linear wave loads; (b) Nonlinear wave loads; (c) Enlarge comparison; and (d) Comparison of residual pore pressure. $(x, z)=(750,-2) \mathrm{m}$. 


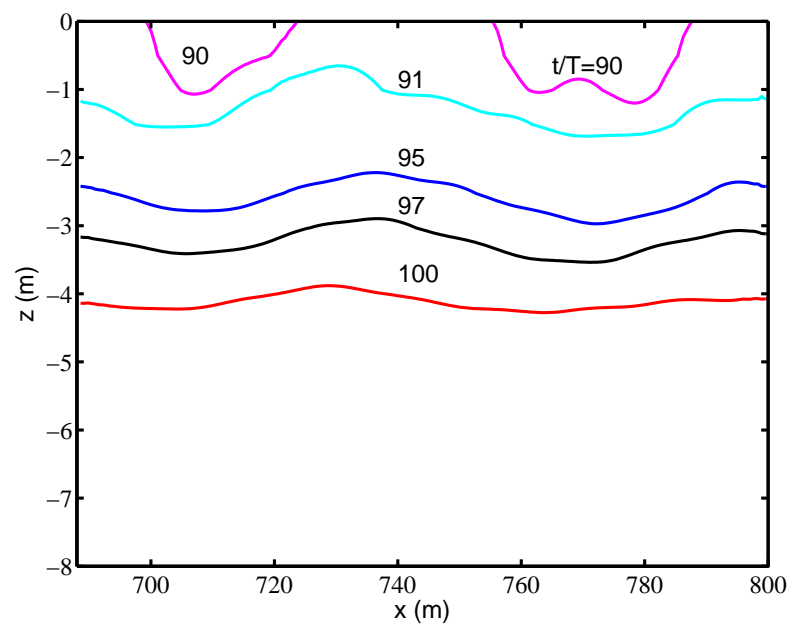

(a) Progressive waves

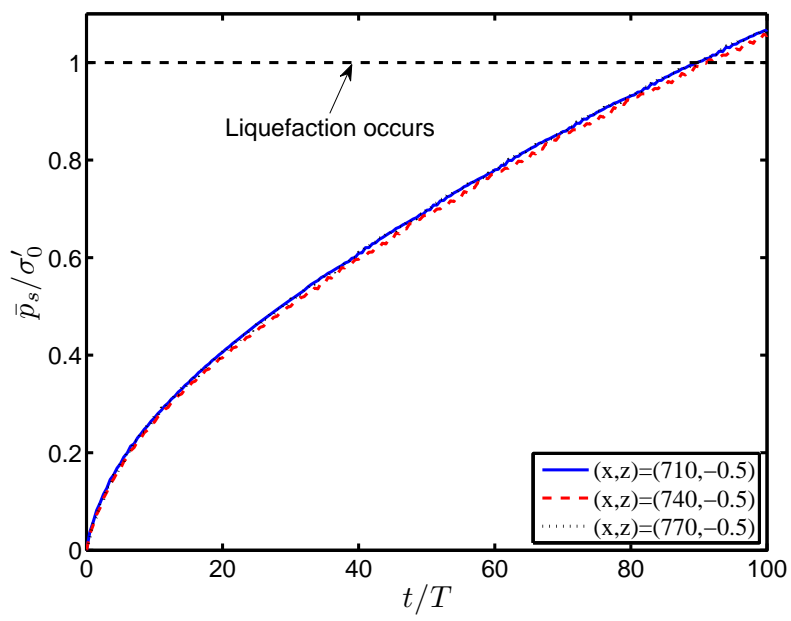

(c) Progressive waves

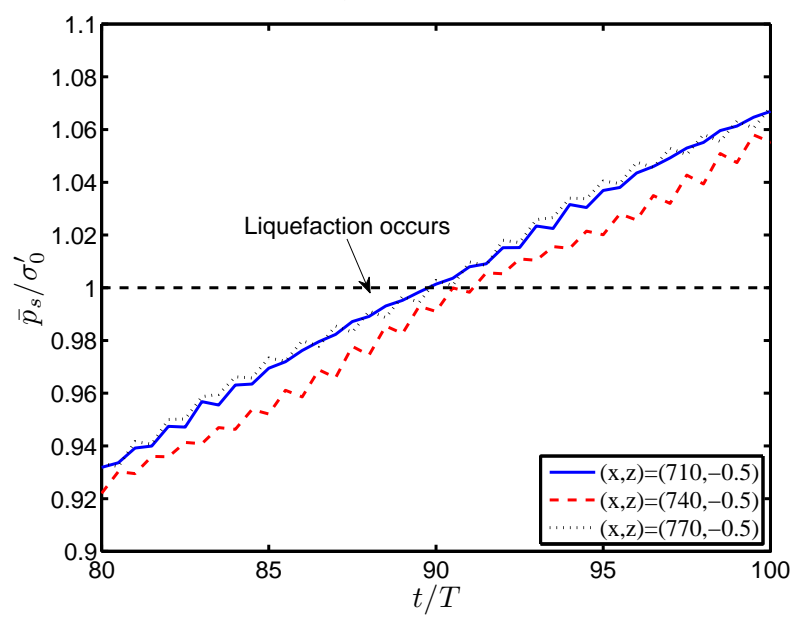

(e) Enlarge of part (c)

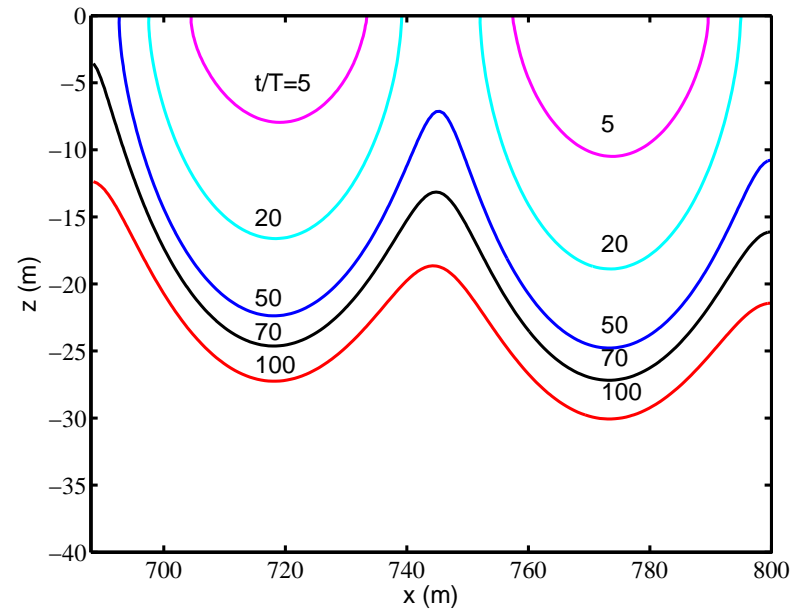

(b) Standing waves

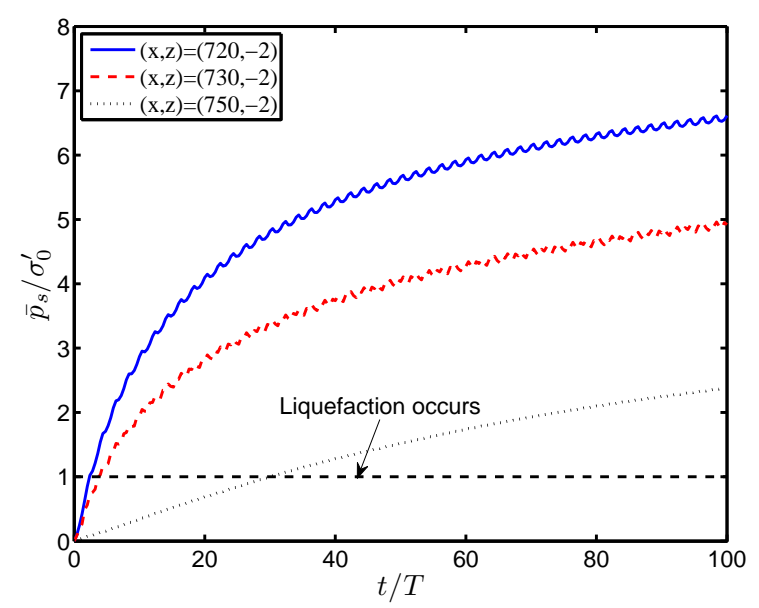

(d) Standing waves

FIG. 7. Tme histories of the development of the liquefaction zone and pore pressure accumulations along the $x$-direction under different types of waves (a) and (b) : liquefaction zones at different time, 4 (c) and (d)enporęlpressiptenthuild, aplat three points; and (e) enclarged section of part (c) 


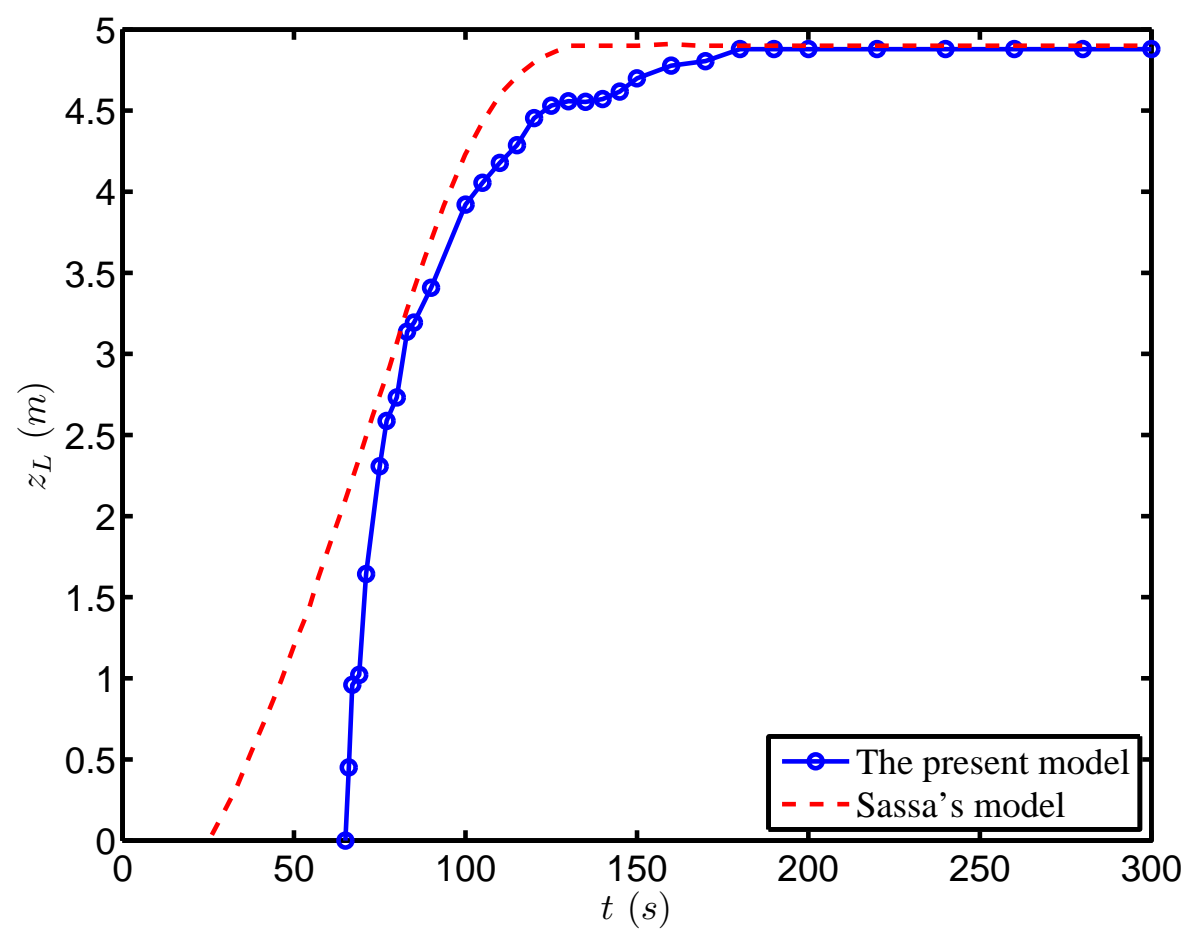

FIG. 8. Comparison of the progression of thewave-induced liquefaction zone versus time between Sassa's model and the present model. 


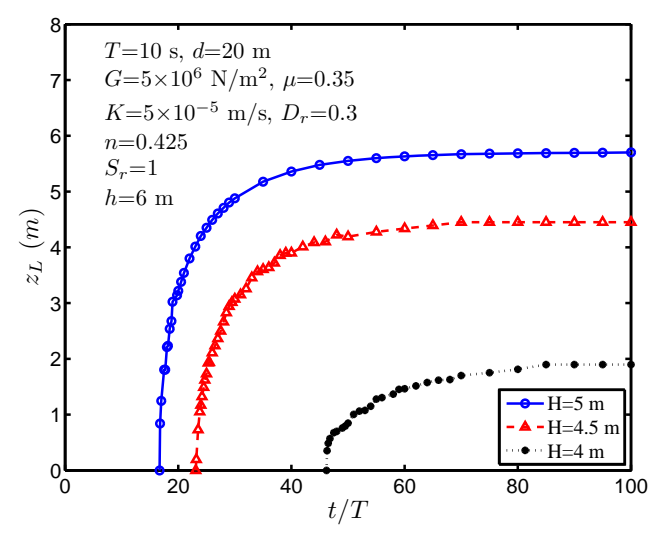

(a) wave height

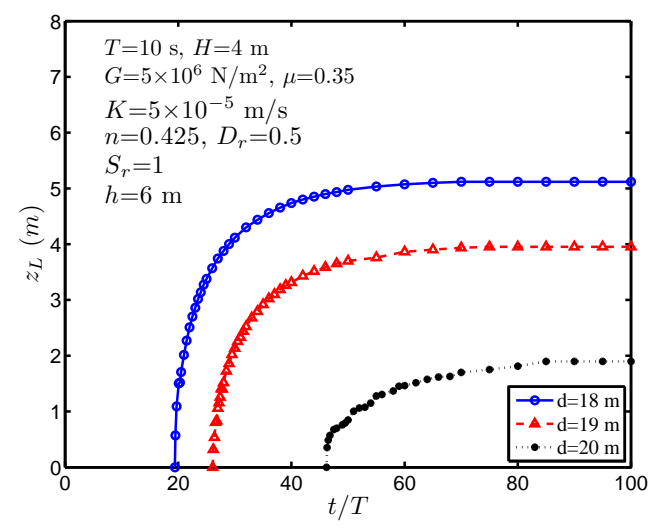

(b) water depth

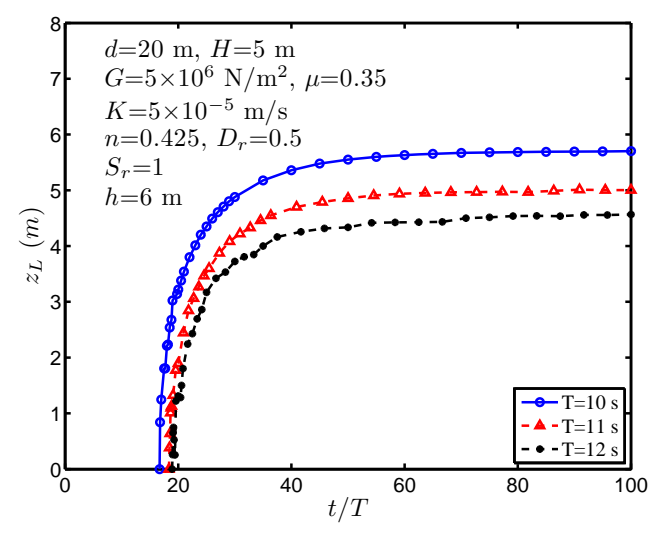

(c) wave period

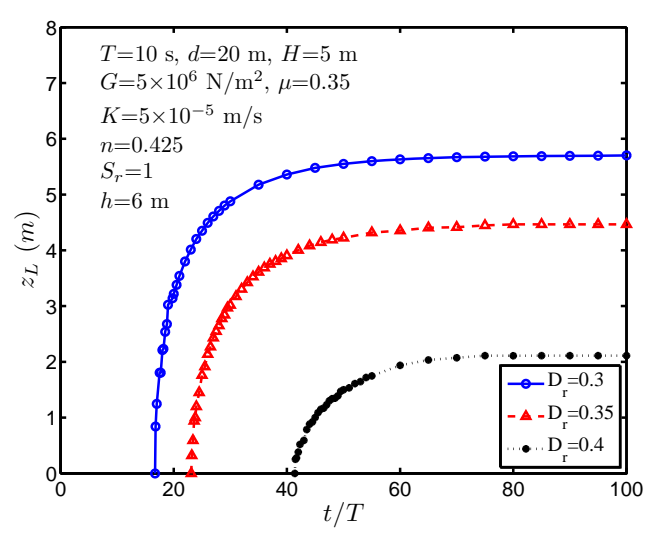

(d) relative density $\left(D_{r}\right)$

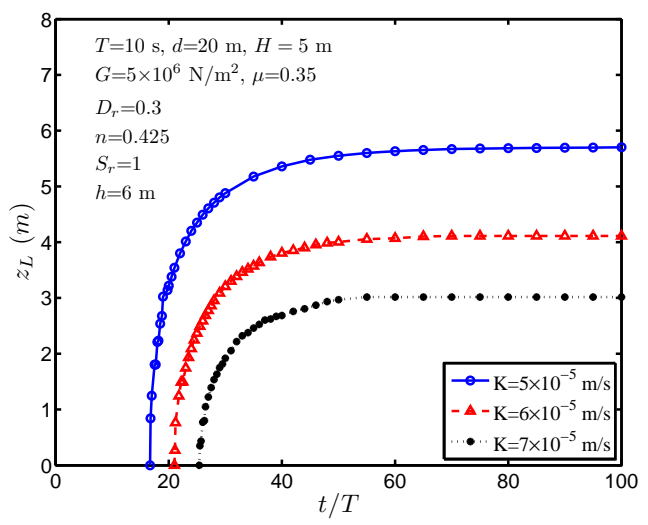

(e) permeability $(K)$

FIG. 9. Parametric studies for progress of wave-induced liquefied zone versus time for various (a)-(c) wave and (d)-(e) soil charcateristics. 